\title{
Correlated traits for dispersal pattern: Terrestrial movement of the water cricket Velia caprai (Heteroptera: Gerromorpha: Veliidae)
}

\author{
TomÁš DITRICH ${ }^{1,2}$ and MirosLAv PAPÁČEK ${ }^{1}$ \\ ${ }^{1}$ Department of Biology, Pedagogical Faculty, University of South Bohemia, Jeronýmova 10, 37115 České Budějovice, \\ Czech Republic; e-mail: ditom@pf.jcu.cz \\ ${ }^{2}$ Department of Ecosystem Biology, Faculty of Science, University of South Bohemia, Branišovská 31, 37005 České Budějovice, \\ Czech Republic
}

Key words. Wing dimorphism, development rate, longevity, terrestrial dispersal, upstream dispersal, Velia caprai, Gerromorpha

\begin{abstract}
Macropterous individuals of wing polymorphic semiaquatic bugs (Heteroptera: Gerromorpha) usually occur at a high frequency if there is a need to leave an unfavorable habitat or in a generation migrating to/from an overwintering site. Velia caprai (Veliidae) is usually found in unpredictable habitats, but the macropterous morph is rare. Laboratory, mesocosm and field experiments were used to test the hypothesis that individuals of this species migrate by walking rather than by flight. Laboratory experiments that focused on the development of macropterous morph under conditions that usually stimulate the development of this morph in water striders were unsuccessful. A high temperature shortened the duration of nymphal development, but no winged specimens of Velia caprai developed in the laboratory when reared under either high or low temperatures, long or short photoperiods or on the surface of water or wet filter paper. Mesocosm experiments with apterous adults revealed they are able to walk on land. Both the males and females dispersed by walking in semi-natural conditions. Long-term field experiments using mark and recapture confirmed that this species can disperse by walking. Apterous individuals can compensate for downstream drift by upstream terrestrial migration and colonize newly established pools and ditches even several tens of meters from source sites. The development of a macropterous morph in response to environmental factors is replaced by terrestrial dispersal in $V$. caprai.
\end{abstract}

\section{INTRODUCTION}

Most semi-aquatic bugs (Heteroptera: Gerromorpha) exhibit wing polymorphism, as many species have macropterous, brachypterous or apterous morphs (Andersen, 1982). Both genetic and environmental factors determine the wing morph in semi-aquatic bugs (see Spence \& Andersen, 1994). Wing development is costly; so apterous individuals can allocate more energy to reproduction. Thus, apterous and brachypterous females usually have a higher fecundity than macropterous females (Roff \& Fairbairn, 1991). Macropterous individuals thus predominate only if they migrate between ephemeral habitats or to/from overwintering sites. Hence, a general model predicts predominant occurrence of apterous morphs in stable habitats and macropterous morphs in temporary habitats (Vepsäläinen, 1973). In addition the overwintering generation in polyvoltine species is usually macropterous (Spence \& Andersen, 1994; but see Muraji \& Nakasuji, 1988). Environmental factors affecting wing polymorphism are population density (e.g. Muraji \& Nakasuji, 1988; Harada et al., 1997), photoperiod (e.g. Muraji et al., 1989; Spence, 1989), temperature (e.g. Pfenning et al., 2008) and food availability (e.g. Muraji et al., 1989; Pfenning et al., 2007). Desiccation of the habitat prolongs development in Aquarius paludum, but does not affect wing polymorphism (Kishi et al., 2002).

The water cricket, Velia caprai Tamanini, 1947 (Veliidae), colonizes small forest streams, ditches and pools in most European countries (Wróblewski, 1980; Aukema \&
Rieger, 1995). It is predominantly univoltine, but there is probably a second summer generation in warm areas (see e.g., Mielewczyk, 1980; Papáček \& Jandová, 2003; Ditrich \& Papáček, 2009). The forest streams occupied by $V$. caprai are unpredictable habitats as both beds of streams and water level vary during a season. Moreover, this species occupies ephemeral sites (Ditrich et al., 2008). The unpredictable nature of the habitat leads to the assumption that $V$. caprai is macropterous, or at least wing polymorphic. Indeed, this species is pterodimorphic with both macropterous and apterous morphs, but the macropterous morph is rare (Brinkhurst, 1959; Mielewczyk, 1980; Brönmark et al., 1985; Murray \& Giller, 1991; Papáček \& Jandová, 2003). In addition, macropterous adults of predominantly apterous/brachypterous species of Gerridae have a low flight tendency (Fairbairn $\&$ Butler, 1990). Nevertheless, wingless specimens of $V$. caprai quickly colonize newly created water bodies, up to a hundred meters from the closest source (see below). In addition, forest streams inhabited by $V$. caprai frequently flood in spring, which probably results in occasional downstream drift. Insects living in similar habitats (mostly Ephemeroptera, Plecoptera and Trichoptera larvae) exhibit upstream dispersal, with adults flying upstream to compensate for the downstream drift of the larvae (Müller, 1982). Upstream dispersal is thus also likely to occur in $V$. caprai. However, the almost complete absence of winged morphs in many populations of $V$. caprai makes the maintenance of populations in the upper parts of streams puzzling. 
These facts lead to a hypothesis - V. caprai can disperse by walking, as it differs from other gerromorphan bugs in the way it walks. When on a water surface, Velia spp. moves by rowing (synchronous moving of middle legs); when on land, it moves like other terrestrial insects (Andersen, 1995). If $V$. caprai disperses terrestrially, it has probably lost or has a reduced incidence of macropterous morphs in response to environmental factors.

Recent laboratory experiments carried out concurrently with this study indicate that $V$. caprai does not produce significantly more winged individuals when crowded during nymphal development. The effect of other environmental factors, which induce the development of winged specimens in other gerromorphan species, on the induction of wing morphs in $V$. caprai, is also determined in this paper. Terrestrial dispersal was studied in both the field and mesocosms. None of these three experiments was extensive. However, they provide a framework for studying terrestrial dispersal in $V$. caprai. The mesocosm experiments were designed to reveal whether this species is capable of terrestrial movement and the mark - recapture study to determine whether terrestrial dispersal occurs in nature. This study is thus a combination of three approaches, focused on one phenomenon. It does not examine how far, how often or what part of a population of $V$. caprai disperses terrestrially, but only if it disperses in this way.

\section{MATERIAL AND METHODS}

\section{Laboratory experiments}

The response of wing polymorphism to increased temperature, decreased photoperiod and substrate desiccation was determined in a laboratory experiment in spring 2007. This was done by rearing larvae in the following conditions: (i) high $23 \pm 2{ }^{\circ} \mathrm{C}$ or low $12 \pm 2{ }^{\circ} \mathrm{C}$ temperatures; (ii) long (16L: 8D) or short days (12L: 12D); (iii) normal or desiccated (nymphs reared on either a water surface or wet filter paper). The overwintering eggs used in the experiments were collected from moss growing along several streams in the Novohradské Hory Mts (Czech Republic). Eggs were kept at either (i) $23 \pm 2{ }^{\circ} \mathrm{C}$ or (ii) $12 \pm 2^{\circ} \mathrm{C}$ on wet filter paper. The hatchling nymphs were reared in one of six different conditions: (i) high temperature, long day, on water (ii) high temperature, long day, on paper (iii) high temperature, short day, on water (iv) high temperature, short day, on paper (v) low temperature, long day, on water or (vi) low temperature, short day, on water. For each treatment, 20 first instar nymphs were placed in each of two plastic containers $(33 \times 11 \times 13 \mathrm{~cm})$. Wet filter paper was put at the bottom of the reared-on-paper treatment containers; other containers were filled with tap water to a depth of $2 \mathrm{~cm}$. Nymphs were fed daily with frozen Drosophila melanogaster as follows: 1 fly per $1^{\text {st }}$ and $2^{\text {nd }}$ instar individual; 2 flies per $3^{\text {rd }}$ instar; 3 flies per $4^{\text {th }}$ instar and 4 flies per $5^{\text {th }}$ instar nymph. The containers were checked daily, exuviae and dead nymphs removed immediately and water changed twice a week.

Wing morph, sex and date of emergence of adults were recorded for all adults. As it was impossible to track every individual and accurately determine their rate of development, it was set as the number of days between mean date of of eclosion within the containers and that of imaginal ecdysis. The duration of nymphal development was analyzed using general linear models (factorial ANOVA between (i) temperature and photo- period, and (ii) substrate and photoperiod effect). Mortality among treatments was compared using a generalized linear model (Wald test: binomial distribution, logit link function).

\section{Mesocosm experiment}

An experiment in semi-natural conditions was set up to determine whether and how quickly $V$. caprai is able to traverse at least several meters of terrestrial space by walking. The arena consisted of a cuboid made of hardboard $(275 \times 40 \times 40 \mathrm{~cm})$, but without a top, which when placed on the ground created a passage ( $275 \mathrm{~cm}$ long, $40 \mathrm{~cm}$ wide) with $40 \mathrm{~cm}$ high sides. One end (starting post) was closed and the bottom covered with sand (6-8 $\mathrm{cm}$ deep, area ca $1,000 \mathrm{~cm}^{2}$ ) and the rest of the passage with moss (mostly Sphagnum spp. and Polytrichum spp.) and natural obstacles like branches and stones. A plastic container $(60 \times 40 \times 35 \mathrm{~cm})$ containing a $5 \mathrm{~cm}$ depth of water was placed at the open end (finish). This end was constructed so that the migrants would fall into the container and have no possibility of escaping. The arena was covered with gauze to prevent disturbance from outside and escape of bugs. The experiment was started in September 2008 with 50 specimens (sex-ratio $1: 1$ ) placed at a starting post (on the sand). The container of water at the end of the course was checked for individuals every 6 hours (except at night) for two days. Every bug could either aestivate/hide in the moss or under stones, or walk the length of the passage. Temperature and humidity were recorded using an EBI 20TH datalogger. The arena was moistened if the humidity in moss decreased below $85 \%$. There were four replicates; all started at 8 a.m. The moss was changed before each replicate. Data were analyzed using survival analysis and the difference in the dispersal rate of the sexes compared using Gehan-Wilcoxon test.

\section{Field experiment}

A mark-recapture study was used to determine if terrestrial dispersal occurs under natural conditions. Two streams (A and $B$; width varying $30-130 \mathrm{~cm}$, maximum depth ca $30 \mathrm{~cm}$ ) in the Novohradské Hory Mts were chosen for this study in autumn 2007. The pronotum of individuals in a restricted (ca 5-7 $\mathrm{m}$ of the stream with natural rapids or minute downfalls upstream and downstream) subpopulation in every stream was each marked with a dot of coloured nail polish. A total of 134 specimens (86 on stream A, 48 stream B; all wingless) were marked in October 2007. Original sampling sites, other parts of the stream and ephemeral ditches and puddles close by were searched for marked specimens in spring, summer and autumn the following year. Terrestrial dispersal was classified as significant if a marked bug was found either (i) upstream from the sampling site (as dispersion on the water surface is impossible not only through rapids with relatively fast flowing water but also over a barrier like a natural weir) or (ii) on a ditch or puddle not connected with the original stream. Marked bugs were released immediately after recapture. Using a non-individual marking system it was not possible to distinguish a recaptured bug from one recaptured in the past at the same site. However, this method is sufficient for indicating if at least some individuals are capable of terrestrial dispersal.

\section{RESULTS}

\section{Survival rate}

There was a significant effect of temperature on mortality $\left(\right.$ Wald $=17.57$, d.f. $\left.=1, \mathrm{p}<10^{-4}\right): 63.75 \%(\mathrm{n}=80)$ and $28.75 \%(n=160)$ of the nymphs completed their development at $12^{\circ} \mathrm{C}$ and $23^{\circ} \mathrm{C}$, respectively. No effect of photoperiod was found $($ Wald $=0.04$, d.f. $=1, p=0.84$ ) 
TABLE 1. The results of the ANOVA of the effect of selected environmental factors on the duration of nymphal development. Notes: The only significant result was for the effect of temperature. Data for the photoperiod vs. temperature effect and photoperiod vs. substrate effect were analyzed separately.

\begin{tabular}{lcccc}
\hline Factor: / Effect: & $\mathrm{SS}$ & d.f. & $\mathrm{F}$ & $\mathrm{p}$ \\
\hline Temperature & 18,900 & 1 & $3,635.75$ & $<10^{-6}$ \\
Photoperiod & 1.5 & 1 & 0.28 & 0.6 \\
Temperature * photoperiod & 4.7 & 1 & 0.91 & 0.34 \\
Error & 369.1 & 71 & & \\
Photoperiod & 0.03 & 1 & 0.01 & 0.93 \\
Substrate & 0.1 & 1 & 0.03 & 0.86 \\
Photoperiod * substrate & 0.93 & 1 & 0.28 & 0.6 \\
Error & 141.66 & 42 & &
\end{tabular}

as survival was $40.83 \%(\mathrm{n}=120)$ under long day and $40 \%(\mathrm{n}=120)$ under short day conditions. A photoperiod and temperature interaction had not significant effect on mortality (Wald $=0.04$, d.f. $=1, p=0.85$ ). Survival of nymphs reared on filter paper was $27.5 \%(n=80)$ and did not differ significantly from that of nymphs reared on the water surface at the same temperature $(30 \%, \mathrm{n}=80$; Wald $=0.12$, d.f. $=1, p=0.73)$. The photoperiod and substrate interaction effect on mortality was also not significant (Wald $=0.49$, d.f. $=1, p=0.49$ ).

\section{Nymphal development rate}

The overall sex ratio of the newly moulted adults was $46: 51$ (males : females). As there were no significant differences in the duration of nymphal development between the sexes (all treatments; $t$-test, $t=0.6$, d.f. $=95$, $\mathrm{p}=0.55)$, these data were pooled. Temperature had a strong significant effect on the duration of nymphal development (Table 1). The mean duration at the high temperature was 26.37 days and 60.55 days at the low temperature (Table 2). Photoperiod and type of substrate had no significant effect on the duration of postembryonic development (Table 1).

\section{Wing morphs}

All the adults were the commonly occurring apterous morph. Neither temperature, photoperiod nor desiccation induced the development of winged adults.

\section{Mesocosm experiment}

Most of the individuals $(81 \%$ of males, $66 \%$ of females) passed through the passage within the first day. Almost all the individuals traversed the track in two days ( $90 \%$ of males and $95 \%$ of females). Most of the migrants arrived at the finish during the morning of both days (Fig. 1). Dispersal rate of males and females differed significantly (survival analysis; Gehan-Wilcoxon test $=-3.71$, $p$ $=0.0002$ ). Males always arrived first at the finish, but the sex ratio of the migrants, that reached the finish after one day and two days, did not differ from the original $1: 1\left(\chi^{2}\right.$ $=1.53$, d.f. $=1, p=0.22 ; \chi^{2}=0.14$, d.f. $=1, p=0.71$; respectively).
TABle 2. Description of the rearing conditions and the statistics for the effect of those conditions on the duration of nymphal development. Temperature in ${ }^{\circ} \mathrm{C}$; daylight in hours; substrate: water - nymphs reared on water surface; paper - nymphs reared on wet filter paper; $\mathrm{N}$ - number of individuals that reached the adult stage, mean and S.D. of the duration of nymphal development in days.

\begin{tabular}{cccccc}
\hline Temperature & Daylight & Substrate & $\mathrm{N}$ & Mean & SD \\
\hline 12 & 12 & water & 25 & 60.12 & 2.71 \\
12 & 16 & water & 26 & 60.96 & 2.05 \\
23 & 12 & water & 11 & 26.55 & 1.63 \\
23 & 16 & water & 13 & 26.30 & 2.25 \\
23 & 12 & paper & 12 & 26.17 & 1.80 \\
23 & 16 & paper & 10 & 26.50 & 1.43 \\
\hline
\end{tabular}

\section{Mark-recapture field experiment}

Results of the field experiment are documented in Table 3. The cases of evident terrestrial dispersal are as follows: Six of the marked specimens dispersed in 2007: stream $\mathrm{A}$ - three females and one male were found more than $20 \mathrm{~m}$ and 5 weirs upstream; stream B - one male and one female were found in a nearby puddle, ca $12 \mathrm{~m}$ airdistance from the original release site. Two females were found ca $15 \mathrm{~m}$ upstream. However, surface dispersal could not be excluded as the water was flowing relatively slowly over the weir between the release and recapture sites. Fifteen terrestrial dispersals of marked adults were recorded in the year 2008: stream A - seven individuals were found more than $20 \mathrm{~m}$ ( 5 weirs) upstream from their release site, one male was found in a nearby (ca $10 \mathrm{~m}$ ) puddle in spring and summer. In addition, two females were found more than $45 \mathrm{~m}$ upstream and had either crossed a road (ca $1.6 \mathrm{~m}$ above the water surface) or passed through a pipe (ca $50 \mathrm{~cm}$ wide, $3 \mathrm{~m}$ long) with slippery sides against a continuous and relatively fast $(15-20 \mathrm{~cm} / \mathrm{s})$ flow of water. Stream B - one female was

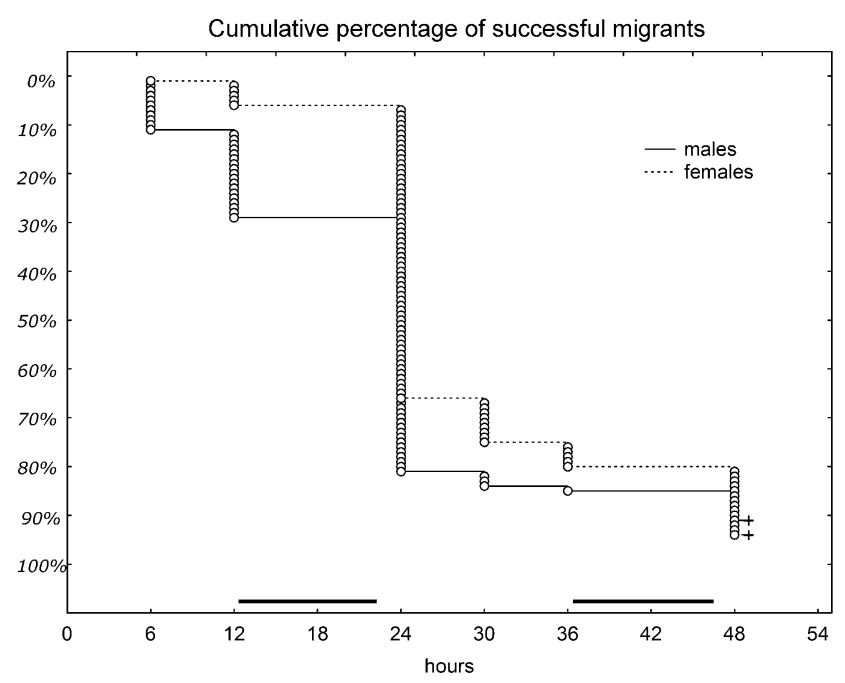

Fig. 1. Kaplan-Meier plot of the cumulative percentage of males and females of $V$. caprai that dispersed over the course of the study. Data from all replicates were pooled; initial $\mathrm{N}$ is 100 males and 100 females. Black lines above hours denote nighttime and a cross the end of the experiment. 
TABLE 3. Results of the mark-recapture field experiment. $\mathrm{N}$ - number of specimens marked at the beginning of the experiment; Orig - Number of marked specimens found at the original sites; Down - number of marked specimens that were found downstream from the original site; $\mathrm{Up}$ - number of migrants that were found upstream from the original site; IWB - number of migrants that were found in isolated water bodies.

\begin{tabular}{|c|c|c|c|c|c|c|c|c|c|c|c|c|c|c|c|c|c|}
\hline \multirow{2}{*}{$\begin{array}{l}\text { Stream and its } \\
\text { drainage area: }\end{array}$} & \multirow{2}{*}{$\mathrm{N}$} & \multicolumn{4}{|c|}{ Autumn 2007} & \multicolumn{4}{|c|}{ Spring 2008} & \multicolumn{4}{|c|}{ Summer 2008} & \multicolumn{4}{|c|}{ Autumn 2008} \\
\hline & & Orig & Down & $\mathrm{Up}$ & IWB & Orig & Down & $\mathrm{Up}$ & IWB & Orig & Down & Up & IWB & Orig & Down & Up & IWB \\
\hline A & 86 & 11 & 0 & 4 & 0 & 8 & 4 & 6 & 1 & 4 & 1 & 3 & 0 & 3 & 1 & 2 & 0 \\
\hline B & 48 & 7 & 1 & 2 & 2 & 4 & 2 & 1 & 0 & 5 & 1 & 1 & 1 & 1 & 0 & 0 & 0 \\
\hline Sum & 134 & 18 & 1 & 6 & 2 & 12 & 6 & 7 & 1 & 9 & 2 & 4 & 1 & 4 & 1 & 2 & 0 \\
\hline
\end{tabular}

found in a pool created by a wind blown tree, ca $40 \mathrm{~m}$ from its release site. Two males were found ca $20 \mathrm{~m}$ upstream above rapids. The last two dispersals were recorded during autumn 2008 at stream A, where one more female crossed the road (see above) and one male was seen ca $40 \mathrm{~m}$ upstream above 7 weirs. These individuals, the same as four more marked (one male, three females) water crickets recaptured in the release sites were still active before overwintering a second time. One female at the release site was found in copula with an unmarked male in November 2008.

\section{DISCUSSION AND CONCLUSIONS}

High temperatures accelerate nymphal development and increase the percentage of macropterous adults in subpopulations of numerous water striders (see Spence \& Anderson, 1994). Rapid development and ability to fly are certainly advantageous for individuals inhabiting unstable habitats. This study also recorded a positive effect of increased temperature on the rate of nymphal development of a non-gerrid species, V. caprai. However, the environmental factors tested in the current experiments (photoperiod, temperature and desiccation of the habitat) and nymphal population density, tested by different experiments in a parallel study (see above), did not result in a significant increase in the percentage of winged adults in $V$. caprai. This species has probably lost or has little ability to produce a long-winged morph even in unfavorable conditions, although it lives in an unpredictable habitat. It appears that the ability to fly is not important for this species as it disperses in a different way. Indeed, apterous adults of water crickets are able to make at least a short journey over land in semi-natural conditions in the mesocosm. As the nymphs reared on wet filter paper were able to feed on fruit flies placed on the filter paper, adults are probably also able to attack and feed on prey on both land and water. Terrestrial dispersal occurs probably mainly at night. This may be an adaptation to avoid predators on land - nocturnal dispersal can decrease the probability of being seen and caught. Males begin to disperse earlier than females, but the effect of this difference diminishes during the course of a day.

Aquarius najas, a widespread European gerrid, is almost exclusively apterous in Northern Europe and with a higher frequency of winged specimens in Central Europe. This species shows symptoms of geographical variation in wing polymorphism. Ahlroth et al. (1999) found that wing polymorphism in this species is affected by environmental conditions, but assumed it is also partly genetically controlled. The overwintering mortality of apterous individuals is lower than that of macropterous ones. Long winged individuals, handicapped during overwintering in northern populations, have a dispersal advantage in the south. A mechanism for wing development is thus maintained in this species.

In contrast, there is a higher frequency of macropterous individuals in some northern populations of $V$. caprai than in the south (cf. Brönmark et al., 1985; Papáček \& Jandová, 2003). In the case of terrestrial dispersal of apterous individuals in $V$. caprai, the macropterous individuals do not have a dispersal advantage, which could have resulted in a strong evolutionary reduction in the mechanism of wing development in this species. Because long-winged individuals are rare and appear infrequently in some populations, it is possible that wing polymorphism is under genetic control in this species.

Apterous adults of $V$. caprai were recorded dispersing, even in natural populations. Wingless water crickets appeared in water bodies isolated from "typical habitats" of this species, which they could only reach by walking over land. These water bodies do not serve only as "stepping stones" during dispersal. Field observations suggest that all the postembryonic stages of this species occur at such sites and they are suitable habitats for facultative reproduction, or at least oviposition. Results also suggest upstream dispersal, however; the migration behaviour of $V$. caprai needs to be studied in more detail. Nevertheless, recolonization of original sites or colonization of new sites (not only upstream) after predictable or unpredictable events (e.g., floods and/or natural downstream drift, etc.) is likely. Subsequent events to water crickets coming on land are: (1) short-term active period on land and return to the water surface, including upstream; (2) quiescent period on land (see Ditrich \& Papáček, 2009) and return, including upstream; (3) active period on land and/or a quiescent period and dispersal over land to other flowing or stable waters in the neighbourhood. An upstream dispersal, sufficient to compensate for downstream drift (i.e., migration s. str.), is not confirmed for the North American gerrid, Aquarius (named as Gerris in original paper) remigis (Fairbairn, 1985), in which the apterous adults inhabit running waters. The terrestrial dispersal of semiaquatic bugs seems to be generally of very little importance (Andersen, 1995; Bowdan, 1978). However, it seems to be important for the water cricket $V$. caprai.

The longevity of $V$. caprai, noted by Ditrich \& Papáček (2008), is confirmed by the field mark-recapture study. 
Some adults, marked in autumn 2007, were still alive in autumn 2008, sexually active and ready to overwinter a second time. Longevity and terrestrial dispersal might be connected. The relatively rapid dispersal by flight in most gerrids is replaced by the surely slower terrestrial dispersal in $V$. caprai. It is possible that some individuals can spend a couple of months dispersing over land and breeding in a new site almost two years after eclosion.

The factors inducing terrestrial dispersal in $V$. caprai, or a period spent living on land and its duration, remain unknown. This study indicate that the occurrence on land of this species is not necessarily for sexual reasons, or because of intraspecific competition (cf. Erlandson, 1993), or for oviposition, or for spending periods quiescent during winter or summer (see Ditrich \& Papáček, 2008, 2009).

ACKNOWLEDGEMENTS. The study was funded by a grant from the Ministry of Education, Youth and Sports of the Czech Republic, No. MSM 6007665801.

\section{REFERENCES}

Ahlroth P., Alatalo R.V., Hyvarinen E. \& Suhonen J. 1999: Geographical variation in wing polymorphism of the waterstrider Aquarius najas (Heteroptera, Gerridae). J. Evol. Biol. 12: $156-160$

ANDERSEN N.M. 1982: The semiaquatic bugs (Hemiptera, Gerromorpha). Phylogeny, adaptations, biogeography, and classification. Entomonograph 3: 1-455.

ANDERSEN N.M. 1995: Cladistic inference and evolutionary scenarios: locomotory structure, function, and performance in water striders. Cladistics 11: 279-295.

Aukema B. \& Rieger C. 1995: Catalogue of the Heteroptera of the Palaearctic Region. Vol. 1. Netherlands Entomological Society, Amsterdam, $222 \mathrm{pp}$.

BOWDAN E. 1978: Walking and rowing in the water strider, Gerris remigis. J. Comp. Physiol. (A) 123: 43-49.

BRINKHURST R.O. 1959: Alary polymorphism in the Gerroidea (Hemiptera - Heteroptera). J. Anim. Ecol. 28: 211-230.

Brönmark C., Malmquist B. \& Otto C. 1985: Dynamics and structure of a Velia caprai (Heteroptera) population in a South Swedish Stream. Holarct. Ecol. 8: 253-258.

DitRICH T. \& PAPÁČEK M. 2008: An unusual life history within semiaquatic bugs: bionomy of Velia caprai Tamanini 1947. In Bryja J., Nedvěd O., Sedláček F. \& Zukal J. (eds): Zoological days České Budějovice 2008. Book of Abstracts from Congress in 14-15th February 2008. Institute of Vertebrate Biology, Brno, 244 pp. [in Czech].

DitRICH T. \& PAPÁČEK M. 2009: Effective strategy of the overwintering of semiaquatic bugs: Overwintering of Velia caprai (Heteroptera: Gerromorpha: Veliidae). J. Nat. Hist. 43: 529-543.

Ditrich T., PAPÁČEK M. \& Broum T. 2008: Spatial distribution of semiaquatic bugs (Heteroptera: Gerromorpha) and their wing morphs in a small scale of the Pohořský Potok stream spring area (Novohradské Hory Mts.). Silva Gabreta 14: $173-178$

ERLANDSSON A. 1993: Sex ratio changes in the water cricket (Velia caprai): why do males disappear? Aquat. Insects 15: $1-10$.
FAIRBAIRN D.J. 1985: A test of the hypothesis of compensatory upstream dispersal using a stream-dwelling waterstrider, Gerris remigis Say. Oecologia (Berl.) 66: 147-153.

FAIRBAIRN D.J. \& BUTLER T.C. 1990: Correlated traits for migration in the Gerridae (Hemiptera, Heteroptera): a field test. Ecol. Entomol. 15: 131-142.

Harada T., TABUChI R. \& Koura J. 1997: Migratory syndrome in the water strider Aquarius paludum (Heteroptera: Gerridae) reared in high versus low nymphal densities. Eur. J. Entomol. 94: 445-452.

Kishi M., Harada T. \& Spence J.R. 2002: Adult flight in a water strider exposed to habitat drydown in the larval stages. Naturwissenschaften 89: 552-554.

MielewCZYK S. 1980: Zur Ökologie, Biologie und Morphologie von Velia saulii Tam. und V. caprai Tam. (Heteroptera, Veliidae). Ann. Zool. (Wars.) 35: 285-305.

MÜLLER K. 1982: The colonization cycle of freshwater insects. Oecologia (Berl.) 52: 202-207.

Muraji M., Miura T. \& NakasujI F. 1989: Phenological studies on the wing dimorphism of a semi-aquatic bug, Microvelia douglasi (Heteroptera: Veliidae). Res. Popul. Ecol. 31: 129-138.

Muraji M. \& NaKasujI F. 1988: Comparative studies on life history traits of three wing dimorphic water bugs, Microvelia spp. Westwood (Heteroptera: Veliidae). Popul. Ecol. 30: 315-327.

MurRay A.M. \& Giller P.S. 1991: Life history and overwintering tactics of Velia caprai Tam. (Hemiptera: Veliidae) in Southern Ireland. Aquat. Insects 13: 229-243.

PAPÁČEK M. \& JANDOVÁ L. 2003: Extreme variability of life history in the water cricket Velia caprai, Tamanini 1947 (Heteroptera: Gerromorpha: Veliidae): the study under the environmental conditions of the Novohradské hory Mts. In Papáček M. (ed.): Biodiversity and Environmental Conditions of the Novohradské hory Mountains. University of South Bohemia and Institute of Entomology, Biology Centre, ASCR, České Budějovice, pp. 149-162 [in Czech, English abstr.].

Pfenning B., Gerstner S. \& Poethke H.J. 2008: Alternative life histories in the water strider Gerris lacustris: time constraint on wing morph and voltinism. Entomol. Exp. Appl. 129: 235-242.

Pfenning B., Poethke H.J. \& Hovestadt T. 2007: Dealing with time constraints on development: the effect of food availability. Ecol. Entomol. 32: 273-278.

RofF D.A. \& FaIRBAIRN D.J. 1991: Wing dimorphisms and the evolution of migratory polymorphisms among the Insecta. Am. Zool. 31: 243-251.

SPENCE J.R. \& ANDERSEN N.M. 1994: Biology of water striders interactions between systematics and ecology. Annu. Rev. Entomol. 39: 101-128.

SPENCE J.R. 1989: The habitat templet and life history strategies of pond skaters (Heteroptera: Gerridae): reproductive potential, phenology, and wing dimorphism. Can. J. Zool. 67: $2432-2447$.

VEPSÄLÄINEN K. 1973: The distribution and habitats of Gerris Fabr. species (Heteroptera, Gerridae) in Finland. Ann. Zool. Fenn. 10: 419-444.

WróBlewsKi A. 1980: True Bugs (Heteroptera). Freshwater Fauna of Poland. Vol. 8. Państwowe Wydawnictwo Naukowe, Warszawa, Poznań, 154 pp. [in Polish].

Received February 25, 2009; revised and accepted May 15, 2009 